\title{
Characteristics of a Type of NTC Thermistors for Cryogenic Applications
}

\author{
Yuqi Lan ${ }^{1,2 *}$, Shenyin Yang2, Guangming Chen'1, Sifeng Yang2 \\ ${ }^{1}$ Institute of Refrigeration and Cryogenics, Zhejiang University, Hangzhou, China \\ ${ }^{2}$ Beijing Institute of Aerospace Testing Technology, Beijing, China \\ Email: ^hangtiandiwen@163.com
}

How to cite this paper: Lan, Y.Q., Yang, S.Y., Chen, G.M. and Yang, S.F. (2020) Characteristics of a Type of NTC Thermistors for Cryogenic Applications. Advances in Materials Physics and Chemistry, 10, 167-177.

https://doi.org/10.4236/ampc.2020.108012

Received: July 15, 2020

Accepted: August 14, 2020

Published: August 17, 2020

Copyright $\odot 2020$ by author(s) and Scientific Research Publishing Inc. This work is licensed under the Creative Commons Attribution International License (CC BY 4.0).

http://creativecommons.org/licenses/by/4.0/

\begin{abstract}
A new type of miniature negative temperature coefficient (NTC) thermistors has been developed and manufactured with $\mathrm{Mn}-\mathrm{Ni}-\mathrm{Cu}-\mathrm{Fe}$ oxides. The prepared NTC thermistors were calibrated in the temperature range from $77 \mathrm{~K}$ to $300 \mathrm{~K}$ with $1 \mu \mathrm{A}$ exciting currents. The automatic calibration apparatus as well as thermometric characteristics, stability, calibration equations and interchangeability of the manufactured thermistors were investigated. A mean fit equation was obtained: $1 / T=8.60 \times 10^{-4}+6.54 \times 10^{-4} \ln \left(R / R_{\text {ref }}\right)+2.46 \times$ $10^{-5} \ln \left(R / R_{\text {ref }}\right)^{2}+9.48 \times 10^{-7} \ln \left(R / R_{\text {ref }}\right)^{3}-2.16 \times 10^{-8} \ln \left(R / R_{\text {ref }}\right)^{4}$. All the prepared NTC thermistors agreed with this fit with an error of $1.5 \mathrm{~K}$. If the greater accuracy is required, a calibration is necessary, and the calibration accuracy is estimated to be $\pm 10 \mathrm{mK}$.
\end{abstract}

\section{Keywords}

Thermometer, Cryogenics, Thermistors, Calibration, Cryostat

\section{Introduction}

Many cryogenic applications require a large number of temperatures to be monitored in various areas of cryogenic engineering and low-temperature physics. The two most commonly used parameters in cryogenic thermometers are voltage and resistance. The widely applied cryogenic temperature sensors include thermocouples, diodes, resistors and capacitors and so on. Resistors can be classified as positive temperature coefficient (PTC) or negative temperature coefficient (NTC) [1] [2] [3]. NTC resistors exhibit a decrease in resistance with an increase in temperature, which is highly resistant to magnetic field-induces errors and ionizing radiation. Most adapted and commercially available for applications in high magnetic fields and radiation are made of carbon, carbon-glass 
and carbon ceramic, fabricated from bulk materials, and films based on ruthenium oxide, and zirconium oxy-nitride. However, their price is high. Therefore, we investigated the feasibility of low-cost NTC thermistors [4] [5] [6].

The advantages of NTC thermistors for temperature measurement are the high sensitivity to yield a high resolution and the high resistivity permits small mass units with fast response. This makes them compatible for using requiring a high output signal over a relatively narrow temperature range [7] [8]. Low-temperature ( $173 \mathrm{~K}$ to $400 \mathrm{~K}$ ) NTC thermistors made of transition metal oxides are applied in industries for temperature measurement, control and compensation in electronic devices. However, cryogenic NTC thermistors for applications below $173 \mathrm{~K}$ have been scarcely reported in detail.

In this paper, the $\mathrm{Mn}-\mathrm{Ni}-\mathrm{Cu}-\mathrm{Fe}$ oxides NTC thermistors of low resistivity were prepared by using the solid-state coordination reaction route, with the in-situ lead wire attachment method (ISAM) and sealed by glass, as described in our previous work [7]. The thermistors were calibrated with a stable exciting current. The thermistors provide good sensitivity over the measurement range from $77 \mathrm{~K}$ to $300 \mathrm{~K}$. And meanwhile, the automatic calibration apparatus, stability, calibration equations and interchangeability of prepared thermistors were also investigated.

\section{Manufacturing Technology of Thermistors}

The NTC ceramics were synthesized through solid-state route. Analytical grade nickel acetate $\mathrm{Ni}\left(\mathrm{CH}_{3} \mathrm{COO}\right)_{2} \cdot 4 \mathrm{H}_{2} \mathrm{O}$, copper acetate $\mathrm{Cu}\left(\mathrm{CH}_{3} \mathrm{COO}\right)_{2} \cdot \mathrm{H}_{2} \mathrm{O}$, manganese acetate $\mathrm{Mn}\left(\mathrm{CH}_{3} \mathrm{COO}\right)_{2} \cdot 4 \mathrm{H}_{2} \mathrm{O}$, iron oxalate $\mathrm{FeC}_{2} \mathrm{O}_{4} \cdot 2 \mathrm{H}_{2} \mathrm{O}$ and oxalic acid $\mathrm{H}_{2} \mathrm{CO}_{4} \cdot 2 \mathrm{H}_{2} \mathrm{O}$ were used as raw materials. The contents of metal ions in raw materials are determined by chemical analysis. The raw materials were accurately weighed according to their molar ratio, transferred to polypropylene jars and milled for $24 \mathrm{~h}$ using zirconia balls as milling medium to get a uniform mixture. The milled was dried at $75^{\circ} \mathrm{C}$, and calcined at $800^{\circ} \mathrm{C}$ for $4 \mathrm{~h}$ in air. The calcined powder was then ground for $48 \mathrm{~h}$ by ball milling to get a narrow particle-size distribution.

Disk-shaped thermistors were designed by using in-situ lead wire attachment method (ISAM). Celluloid board with a height of $2.0 \mathrm{~mm}$ was drilled a row of holes with a diameter of about $3.5 \mathrm{~mm}$, and a distance of about $2.5 \mathrm{~mm}$ between holes, then was grooved at both sides of the centres of holes, and the distance of between two grooves with the depth of $1.0 \mathrm{~mm}$ and the width of $0.05 \mathrm{~mm}$ is 2 $\mathrm{mm}$. Two platinum lead wires ( $0.05 \mathrm{~mm}$ diameter) were placed into two grooves. The powders granulated with a $4 \%$ polyvinyl alcohol (PVA) organic binder were placed in the holes to form green bodies with cold-pressed using a steel die by single-end compaction and pressed at $200 \mathrm{MPa}$ by isopressing process. Celluloid board with green bodies were heated in air to $400^{\circ} \mathrm{C}$ at a rate of $100^{\circ} \mathrm{C} / \mathrm{h}$, kept at that temperature for $2 \mathrm{~h}$ for adequate binder burnout, and subsequently heated to $1150^{\circ} \mathrm{C}$ at a rate $200^{\circ} \mathrm{C} / \mathrm{h}$ and kept at that temperature for $4 \mathrm{~h}$ for sintering. 
The sintered samples were cut, and subsequently soldered copper leads and sealed by glass. So, NTC thermistors were manufactured. Figure 1 shows the schematic of the in-situ lead wire attachment method (ISAM) for manufacturing thermistors [9].

XRD pattern of the sintered experimental sample in Figure 2 shows the presence of single-phase cubic spinel nickel manganite. The SEM microstructure obtained from the surface of the sample sintered at $1150^{\circ} \mathrm{C}$ is given in Figure 3. It is seen that uniformly sized grains are formed during sintering. The amount of porosity is very less, which shows a dense microstructure formation.

\section{Automatic Calibration Apparatus}

Scare any description of the calibration device has presented in the literature, and a simple statement of the calibration device is given here. The automatic calibration apparatus, which was manufactured by Institute of Refrigeration and Cryogenics, Zhejiang University, in 2008, is now in the ownership of Beijing Institute of Aerospace Testing Technology. The automatic calibration equipment consists of three main parts, including cryostat, temperature control system and

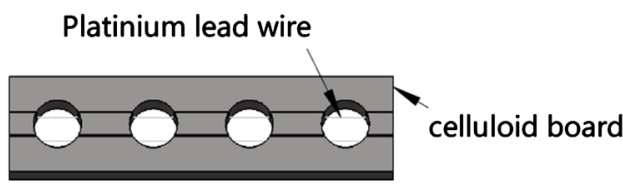

(1)

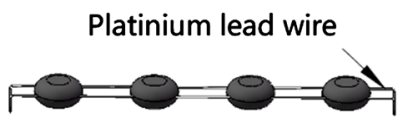

(4)

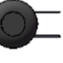

(5)

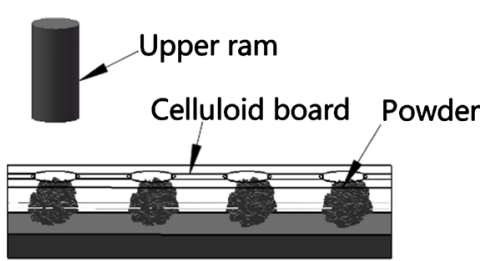

(2)

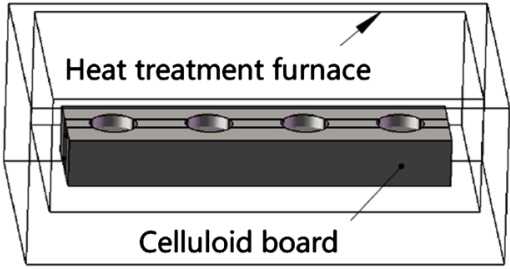

(3)

Figure 1. Schematic of in-situ lead wire attachment method for fabrication of thermistors.

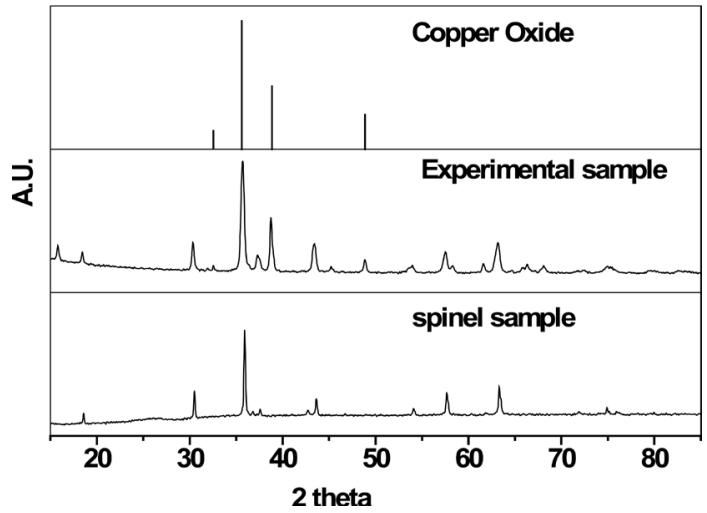

Figure 2. XRD patterns of sintered samples, Copper Oxide and spinel sample. 


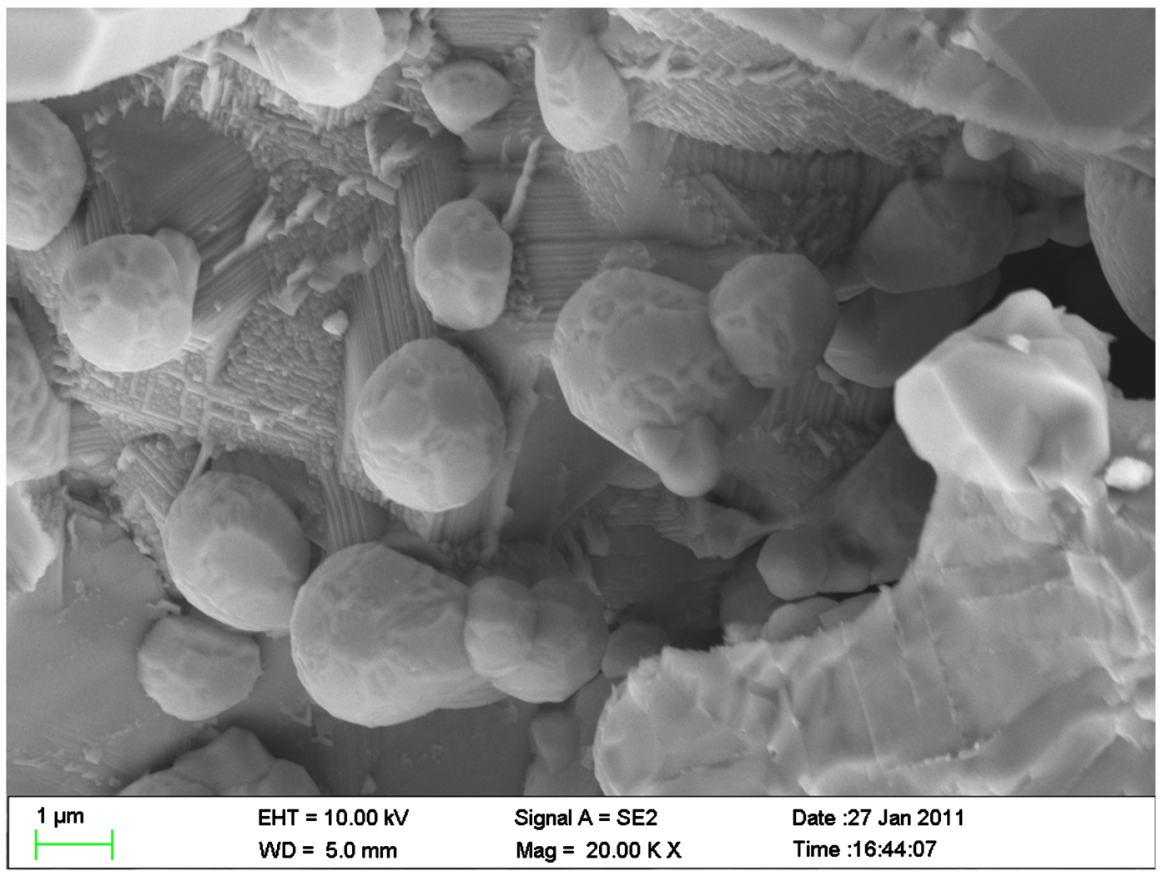

Figure 3. Scanning electron micrographs of surface of the sintered samples.

data acquisition system. Schematic illustration of the automatic calibration facility is shown in Figure 4. The cryostat consists of dewar, evacuation system, vacuum chamber, constant-temperature block, heat sink and some important accessories. The constant-temperature block are uniformly drilled holes on the bottom surface, and hung in an Indium-sealed vacuum can with adiabatic strings in order to reduce the heat leak. A Standard Capsule Platinum Resistance Thermometer (SCPRT, Tinsley 5187L, calibrated by National Institute Metrology of china with the expand uncertainty of $2 \mathrm{mK}$ ) and thermometers were immersed into the holes of the block by silicon grease to guarantee good thermal contact with the block. The leads to each sensor are $6 \mathrm{~m}$ long, and are wound around the heat sink mounted on the top of vacuum can, before reaching a final heat sink on the constant-temperature block. The temperature control system includes a Lakeshore-331s Temperature controller, a Fluke. Model 1590 Supper thermometer II and computer. The computer collects the signals of SCPRT monitored by the Fluke. Model 1590 Supper thermometer II. The control program programmed with Visual Basic regulates the power output of the Lakeshore-331s Temperature controller to heat the heating wire wrapped tightly around the surface the upper part of the constant-temperature block. The segmented Fuzzy-PID (proportional-integral-differential) algorithm is applied in the program. The temperature fluctuation of the cryostat is smaller than $3 \mathrm{mK}$ with $30 \mathrm{~min}$. Data acquisition system consists of Keithley-2400 Source-meter, Keithley-2700 Multi-function meter and the computer. A stable current supplied by Keithley-2400 was applied to the calibrated resistance thermometers. The voltage signals of those thermometers to be calibrated are collected by the computer and stored for the further analysis [10] [11] [12] [13]. 


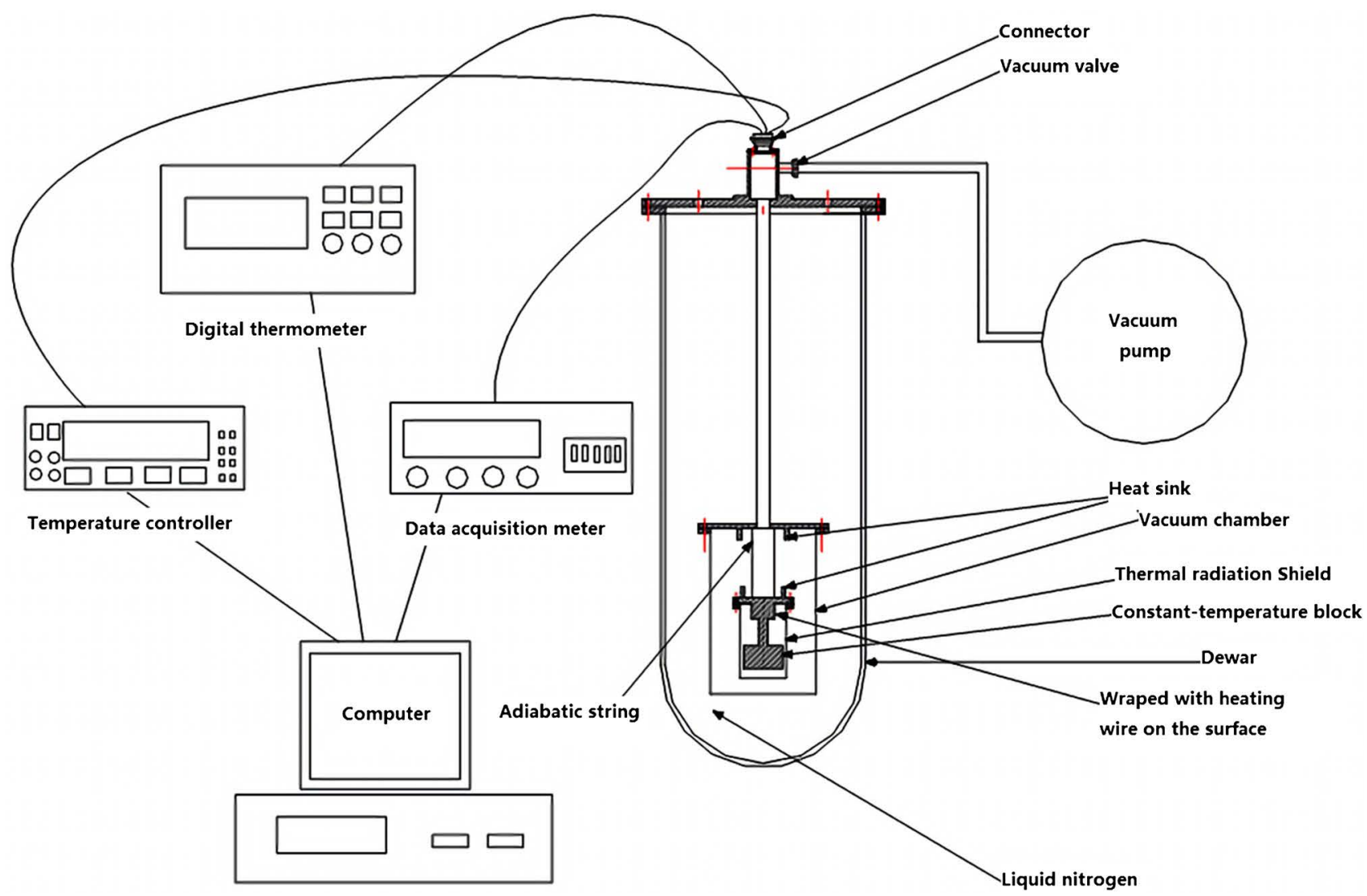

Figure 4. Schematic diagram of the automatic calibration system.

\section{Characteristics of NTC Thermistors}

\subsection{Thermometric Characteristics}

Six thermistors were mounted in the constant-temperature block of the cryostat and driven with a $1 \mu \mathrm{A}$ current. The SCPRT reference thermometer placed in the constant-temperature block was measured by the Fluke. Model 1590 Supper thermometer II. The thermistors calibration was carried out by recording those voltages of calibrated thermistors and reference temperature in the temperature from $77 \mathrm{~K}$ to $120 \mathrm{~K}$ with $5 \mathrm{~K}$ intervals and with $20 \mathrm{~K}$ intervals from $120 \mathrm{~K}$ to 300 $\mathrm{K}$. The calibration tables were obtained by interpolating the calibration data, and averaged to obtain a mean curve. Figure 5 shows the dependence of resistance on the temperature of the six thermistors with the $1 \mu \mathrm{A}$ driving current. The thermistors resistance depends smoothly on over the temperature rang. The variation in thermometric characteristics among thermistors results from the difference of manufacturing techniques.

What shown in Figure 6 is sensitivity, $|S|=|\mathrm{d} R / \mathrm{d} T|$, as functions of temperature in the $77 \mathrm{~K} \sim 300 \mathrm{~K}$ temperature range. The thermistors are more sensitive at temperatures from $77 \mathrm{~K}$ to $140 \mathrm{~K}$. The values of resistance, sensitivity between manufactured NTC thermistors and other thermistors from Lake Shore Company at typical temperature are presented in Table 1 . The prepared NTC thermistors have extremely high resistance and sensitivity in the calibrated tem- 
perature range, which is concluded by comparing those data.

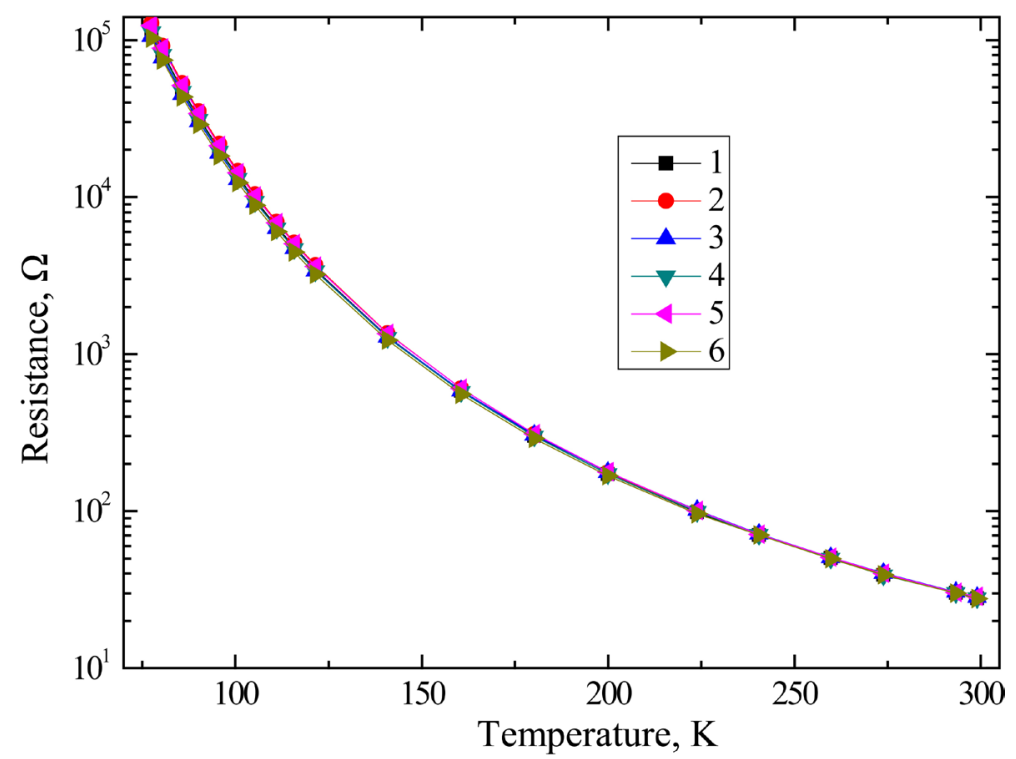

Figure 5. The typical temperature dependences of the six calibrated thermistors.

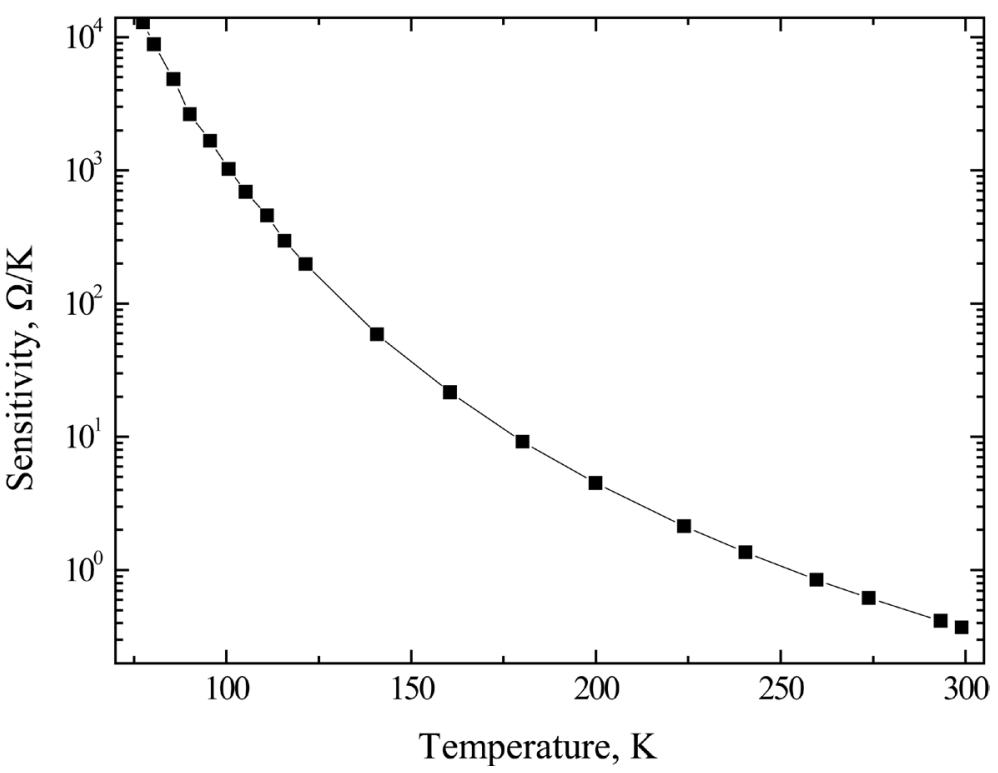

Figure 6. Sensitivity, $|S|=|\mathrm{d} R / \mathrm{d} T|$, versus temperature curves for the ten prepared thermistors.

Table 1. The values of resistance, sensitivity between NTC thermistors and different NTC RTDs from Lake Shore Company at typical temperatures

\begin{tabular}{ccccccccc}
\hline & \multicolumn{2}{c}{ NTC thermistors } & \multicolumn{2}{c}{ CX-1080 } & \multicolumn{2}{c}{ GR-200A-1500 } & \multicolumn{2}{c}{ CGR-1-2000 } \\
\cline { 2 - 9 } $\mathrm{T}(\mathrm{K})$ & $\mathrm{R}(\Omega)$ & $\begin{array}{c}\mathrm{dR} / \mathrm{dT} \\
(\Omega / \mathrm{K})\end{array}$ & $\mathrm{R}(\Omega)$ & $\begin{array}{l}\mathrm{dR} / \mathrm{dT} \\
(\Omega / \mathrm{K})\end{array}$ & $\mathrm{R}(\Omega)$ & $\begin{array}{r}\mathrm{dR} / \mathrm{dT} \\
(\Omega / \mathrm{K})\end{array}$ & $\mathrm{R}(\Omega)$ & $\begin{array}{c}\mathrm{dR} / \mathrm{dT} \\
(\Omega / \mathrm{K})\end{array}$ \\
\hline 77 & 109,000 & -12338.4 & 836 & -115.39 & 5.01 & -0.078 & 21.65 & -0.157 \\
100 & 14200 & -1095.76 & - & - & 3.85 & -0.033 & - & - \\
300 & 27.6 & -0.365 & 130 & -0.55 & - & - & 11.99 & -0.015 \\
\hline
\end{tabular}




\subsection{Stability}

Stability is the closeness of agreement between the results of the measurements of the same measurand carried out under changed conditions of measurements. Preliminary investigation of stability of NTC thermistors at $77 \mathrm{~K}$ was performed. Together with the six calibrated thermistors were immersed in liquid nitrogen for $300 \mathrm{~h}$, and short-term stability data was obtained by subjecting NTC thermistors to 50 thermal shocks from $473 \mathrm{~K}$ to $77 \mathrm{~K}$. Finally, resistance shifts were measured at $77 \mathrm{~K}$ in liquid nitrogen. Deviations of the thermistors resistance corresponded to temperature error in the range from $0.9 \mathrm{mK}$ to $4.7 \mathrm{mK}$. Longterm stability data was obtained by subjecting NTC thermistors to 200 thermal shocks from ambient to liquid nitrogen. The long-term stability for themistors corresponded to temperature error not more than $\pm 8 \mathrm{mK}$ at $77 \mathrm{~K}$. Compared with Germanium, Cernox ${ }^{\mathrm{TM}}$, and Carbon-Glass RTDs, therefore, the stability of NTC thermistors may be much better.

\subsection{Calibration Equations of Thermistors}

As well to known, the performance of the thermistors for temperature measurement is affected by the calibration equation. Chiachung Chen [8] considered the Hoge- 3 equation,

$1 / T=A_{0}+A_{1} \ln \left(R / R_{\text {ref }}\right)+A_{2} \ln \left(R / R_{\text {ref }}\right)^{2}+A_{3} \ln \left(R / R_{\text {ref }}\right)^{3}+A_{4} \ln \left(R / R_{\text {ref }}\right)^{4}$, was the best equation for thermistors by evaluating seven calibration equations. Here, $R$ is the specific resistance ohm value, $R_{\text {ref }}$ is $1 \mathrm{ohm}$, and $T$ is the absolute temperature. The software, MATLAB R2006a, is used to estimate the parameters of calibration equations. The $e_{i}$ was defined as follow: $e_{i}=T_{i}-\hat{T}_{i}$, where $e_{i}$ is the error of calibration equation, $T_{i}$ is the dependent temperature variable and $\hat{T}_{i}$ is the predicted values of calibration equation. Four statistics, $e_{\max }, e_{\min },|e|_{\text {ave }}$ and $e_{s t d}$ are adopted to evaluated the precision of equation. The $e_{\max }$ is the maximum $e_{i}$ value and the $e_{\min }$ is the minimum $e_{i}$ value. The $|e|_{\text {ave }}$ was defined as follow: $|e|_{\text {ave }}=\frac{\sum\left|e_{i}\right|}{n}$, where $\left|e_{i}\right|$ is the absolute value of $e_{i}, \mathrm{n}$ is the number of data. The uncertainty from a calibration equation can be calculated from the standard deviation of the calibration equation: $e_{s t d}=\left(\frac{\left(e_{i}-\bar{e}_{i}\right)^{2}}{n-1}\right)^{0.5}$, where $\bar{e}_{i}$ is the average of $e_{i}$. The values of estimated parameters, $e_{\max }, e_{\min }$, $|e|_{\text {ave }}$ and $e_{\text {std }}$ of calibration equation for six NTC thermistors are listed in Table 2 . The $e_{\max }, e_{\min },|e|_{\text {ave }}$ and $e_{\text {std }}$ values are relatively small, which show the Hoge-3 equation has good precision performance for prepared thermistors. The residual plots the calibration equation for the six thermistors are presented in Figure 7.

\subsection{Interchangeability}

It is very convenient and cost effective to have temperature sensors that match a standard curve, thus not requiring individual calibration. The mean calibration 
table of the thermistors for the temperature range from $77 \mathrm{~K}$ to $300 \mathrm{~K}$ is of most interest to us for the future use. So mean table of resistance versus temperature of the six calibrated thermistors was established, and fitted with the Hoge- 3 equation. A mean fit equation was obtained: $1 / T=8.60 \times 10^{-4}+6.54 \times 10^{-4} \ln \left(R / R_{\text {ref }}\right)+2.46$ $\times 10^{-5} \ln \left(R / R_{\text {ref }}\right)^{2}+9.48 \times 10^{-7} \ln \left(R / R_{\text {ref }}\right)^{3}-2.16 \times 10^{-8} \ln \left(R / R_{\text {ref }}\right)^{4}$. Figure 6 shows

Table 2. The values of estimated parameters, $e_{\max }, e_{\min },|e|_{\text {ave }}$ and $e_{\text {std }}$ of calibration equation for six NTC thermistors.

\begin{tabular}{|c|c|c|c|c|c|c|}
\hline Sample No. & & ameters & $e_{\max }(\mathrm{mK})$ & $e_{\min }(\mathrm{mK})$ & $|e|_{\text {ave }}(\mathrm{mK})$ & $e_{s t d}(\mathrm{mK})$ \\
\hline \multirow[t]{5}{*}{1} & A0 & $8.64 \times 10^{-4}$ & 9.6 & -5.1 & 2.53 & 3.41 \\
\hline & $\mathrm{A} 1$ & $6.59 \times 10^{-4}$ & & & & \\
\hline & $\mathrm{A} 2$ & $2.35 \times 10^{-5}$ & & & & \\
\hline & $\mathrm{A} 3$ & $1.06 \times 10^{-6}$ & & & & \\
\hline & A4 & $-2.26 \times 10^{-8}$ & & & & \\
\hline \multirow[t]{5}{*}{2} & A0 & $9.18 \times 10^{-4}$ & 8.31 & -7.36 & 3.03 & 3.98 \\
\hline & $\mathrm{A} 1$ & $6.45 \times 10^{-4}$ & & & & \\
\hline & $\mathrm{A} 2$ & $2.37 \times 10^{-5}$ & & & & \\
\hline & $\mathrm{A} 3$ & $9.28 \times 10^{-7}$ & & & & \\
\hline & A4 & $-1.99 \times 10^{-8}$ & & & & \\
\hline \multirow[t]{5}{*}{3} & A0 & $8.11 \times 10^{-4}$ & 7.87 & -6.25 & 2.84 & 3.60 \\
\hline & $\mathrm{A} 1$ & $6.62 \times 10^{-4}$ & & & & \\
\hline & A2 & $2.30 \times 10^{-5}$ & & & & \\
\hline & $\mathrm{A} 3$ & $1.21 \times 10^{-6}$ & & & & \\
\hline & A4 & $-2.84 \times 10^{-8}$ & & & & \\
\hline \multirow[t]{5}{*}{4} & A0 & $8.26 \times 10^{-4}$ & 9.12 & -6.74 & 2.45 & 3.45 \\
\hline & $\mathrm{A} 1$ & $6.57 \times 10^{-4}$ & & & & \\
\hline & A2 & $2.63 \times 10^{-5}$ & & & & \\
\hline & $\mathrm{A} 3$ & $7.90 \times 10^{-7}$ & & & & \\
\hline & A4 & $-1.87 \times 10^{-8}$ & & & & \\
\hline \multirow[t]{5}{*}{5} & A0 & $8.85 \times 10^{-4}$ & 7.77 & -4.94 & 2.49 & 3.21 \\
\hline & $\mathrm{A} 1$ & $6.43 \times 10^{-4}$ & & & & \\
\hline & $\mathrm{A} 2$ & $2.55 \times 10^{-5}$ & & & & \\
\hline & A3 & $8.20 \times 10^{-7}$ & & & & \\
\hline & A4 & $-1.77 \times 10^{-8}$ & & & & \\
\hline \multirow[t]{5}{*}{6} & A0 & $8.56 \times 10^{-4}$ & 9.96 & -5.98 & 2.90 & 3.78 \\
\hline & $\mathrm{A} 1$ & $6.56 \times 10^{-4}$ & & & & \\
\hline & A2 & $2.55 \times 10^{-5}$ & & & & \\
\hline & A3 & $9.74 \times 10^{-7}$ & & & & \\
\hline & $\mathrm{A} 4$ & $-2.28 \times 10^{-8}$ & & & & \\
\hline
\end{tabular}




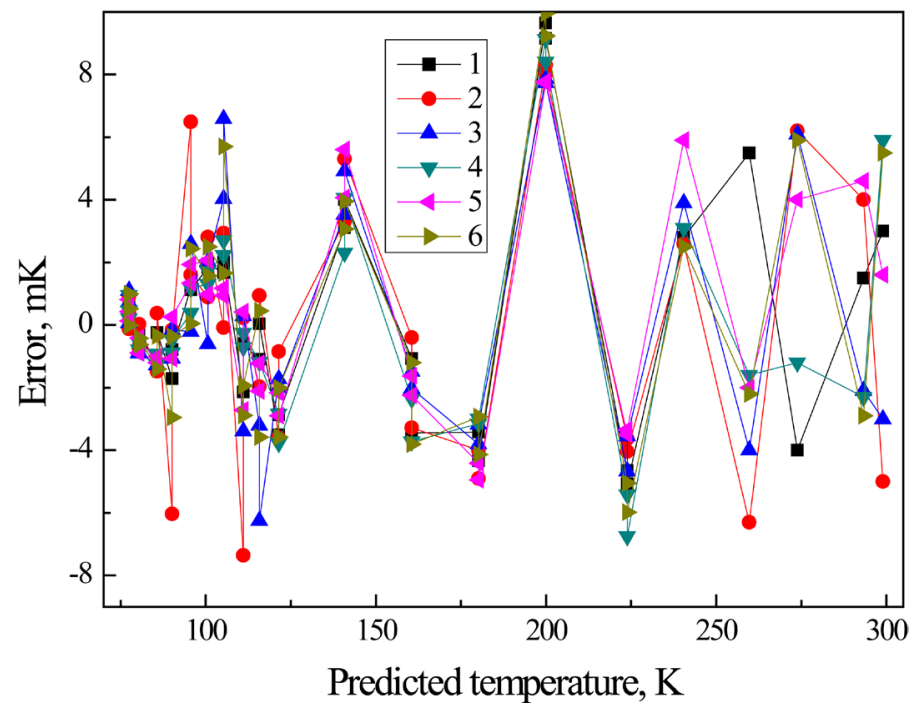

Figure 7. The residual plots of calibration equation for six NTC thermistors.

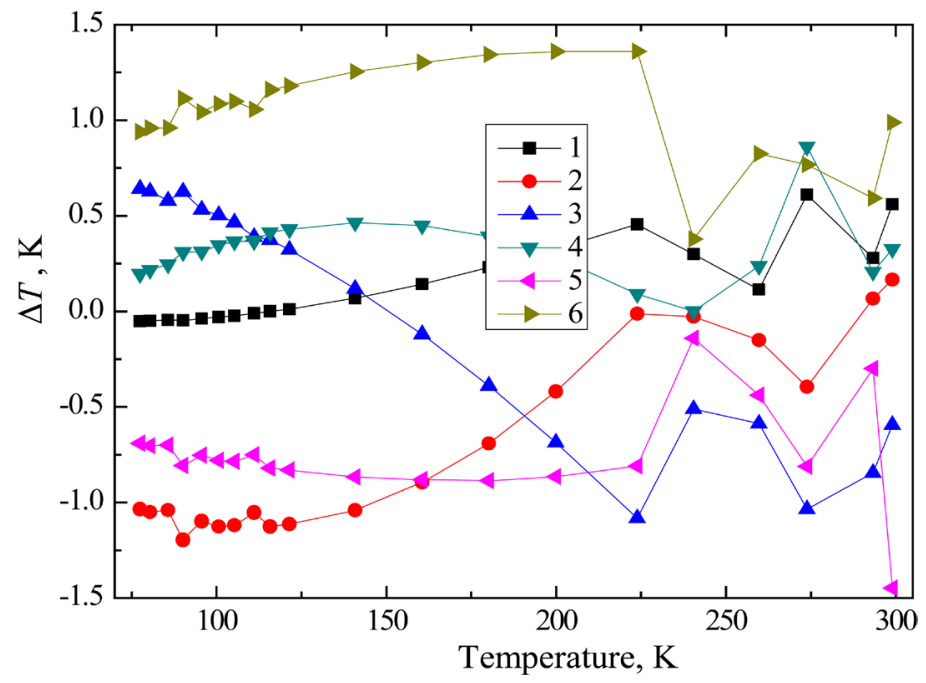

Figure 8. The dependence of the temperature deviation $\Delta T$ of the six calibrated NTC thermistors from their mean fit curve on the temperature.

the dependence of the temperature deviation $\Delta T$ of the six calibrated NTC thermistors from their mean fit curve on the temperature. The deviations from the mean curve are combined with the variation among the NTC thermistors, which is concluded that application of the mean curve will resulted in a measurement of error of $\pm 1.5 \mathrm{~K}$ in the temperature range from $77 \mathrm{~K}$ to $300 \mathrm{~K}$. Therefore, to significantly improve on accuracy, specific calibration of the prepared NTC thermistors is required, and the calibration accuracy is estimated to be $\pm 10 \mathrm{mK}$, which is shown in Figure 8.

\section{Conclusion}

A new type of NTC thermistors had been designed, manufactured and calibrated in the temperature range from $77 \mathrm{~K}$ to $300 \mathrm{~K}$. They showed good thermometric properties, stability and high thermal sensitivity. The accuracy and precision of 
the prepared thermistors with the Hoge- 3 equation fit were as good as other commercial NTC Resistors. A mean fit equation was obtained: $1 / T=8.60 \times 10^{-4}$ $+6.54 \times 10^{-4} \ln \left(R / R_{\mathrm{ref}}\right)+2.46 \times 10^{-5} \ln \left(R / R_{\mathrm{ref}}\right)^{2}+9.48 \times 10^{-7} \ln \left(R / R_{\mathrm{ref}}\right)^{3}-2.16 \times$ $10^{-8} \ln \left(R / R_{\mathrm{ref}}\right)^{4}$. All the prepared NTC thermistors agreed with this fit with an error of $1.5 \mathrm{~K}$. If the greater accuracy is required, a calibration is necessary, and the calibration accuracy is estimated to be $\pm 10 \mathrm{mK}$. Therefore, their widespread application is important in cryogenic engineering and experimental physics.

\section{Acknowledgements}

This work was supported in part by Beijing Institute of Aerospace Testing Technology and Material Physics and Chemistry Research Center of the Xingjiang Technical Institute of Physics and Chemistry, the Chinese Academy of Science. The authors are grateful to Ying Wang, Xue Dong and Dongfang Wang for measuring the six prepared thermistors.

\section{Conflicts of Interest}

The authors declare no conflicts of interest regarding the publication of this paper.

\section{References}

[1] Brandt, B.L., Liu, D.W. and Rubin, L.G. (1999) Low Temperature Thermometry in High Magnetic Fields. VII. Cernox ${ }^{\mathrm{Tm}}$ Sensors to 32 T. Review of Scientific Instruments, 70, 104. https://doi.org/10.1063/1.1149549

[2] Wang, C.C., Akbar, S.A., Chen, W. and Schorr, J.R. (1997) High-Temperature Thermistors Based on Yttria and Calcium Zirconate. Sensors and Actuators A, 58, 237. https://doi.org/10.1016/S0924-4247(97)01394-0

[3] Boltovets, N.S., Kholevchuk, V.V., Konakova, R.V., Mitin, V.F. and Venger, E.F. (2001) Ge-Film Resistance and Si-Based Diode Temperature Microsensors for Cryogenic Applications. Sensors and Actuators A, 92, 191-196. https://doi.org/10.1016/S0924-4247(01)00562-3

[4] Ruby, R.L. and Kempson, M. (1996) Cryogenic Temperature Measurement. Revue Générale de Thermique, 35, 338-343. https://doi.org/10.1016/S0035-3159(99)80076-2

[5] Minti, V.F., Kholevchuk, V.V. and Kolodych, B.P. (2011) Ge-on-GaAs Film Resistance Thermometers: Low-Temperature Conduction and Magnetoresistance. Cryogenics, 51, 68-73. https://doi.org/10.1016/j.cryogenics.2010.11.003

[6] Minti, V.F., Venger, E.F., Boltovets, N.S., Oszwaldowski, M. and Berus, T. (1998) Low-Temperature Ge Film Resistance Thermometers. Sensors and Actuators A, 68, 303-306. https://doi.org/10.1016/S0924-4247(98)00023-5

[7] Shieh, J., Huber, J.E., Fleck, N.A. and Ashby, M.F. (2011) The Selection of Sensors. Progress in Materials Science, 46, 461-504. https://doi.org/10.1016/S0079-6425(00)00011-6

[8] Chen C.C. (2009) Evaluation of Resistance-Temperature Calibration Equations for NTC Thermistors. Measurement, 42, 1103-1111. https://doi.org/10.1016/j.measurement.2009.04.004

[9] Lan, Y.Q., Yu, L.H., Chen, G.M., Yang, S.F. and Chang, A.M. (2010) Construction 
and Characterization of NTC Thermistors at Low Temperature. International Journal of Thermophysics, 31, 1456-1465.

https://doi.org/10.1007/s10765-010-0790-0

[10] Ricketson, B.W.A. and Watkins, R.E.J. (2009) The $27 \Omega$ Rhodium-Iron Ceramic Sensor. Cryogenics, 49, 320-325. https://doi.org/10.1016/j.cryogenics.2009.03.006

[11] Chen, G.M., Gao, X., Zhang, S.Z., Chen, Q. and Lan, Y.Q. (2010) Development of an Automatic Calibration Device for High-Accuracy Low Temperature Thermometers. Science China Technological Sciences, 53, 2404-2407. https://doi.org/10.1007/s11431-010-4020-6

[12] Zhang, P., Xu, Y.X., Wang, R.Z. and Murakami, M. (2003) Fractal Study of the Fluctuation Characteristic in the Calibration of the Cryogenic Thermocouples. Cryogenics, 43, 53-58. https://doi.org/10.1016/S0011-2275(03)00004-3

[13] Rijpma, A.P. and ter Brake, H.J.M. (2006) Cryogenic Thermometry with a Common Diode: Type BAS16. Cryogenics, 46, 68-69.

https://doi.org/10.1016/j.cryogenics.2005.11.009 